\title{
Reflexões sobre Políticas de Educação Linguística em Contexto Plurilíngue
}

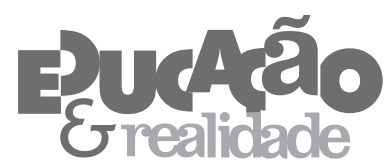

\author{
Maristela Pereira Fritzen' \\ Luana Ewald'
}

'Universidade Regional de Blumenau (FURB), Blumenau/SC - Brasil

RESUMO - Reflexões sobre Políticas de Educação Linguística em Contexto Plurilíngue. Pretende-se neste artigo discutir dados parciais de uma pesquisa de viés qualitativo-interpretativista a fim de abordar os conflitos linguísticos e identitários gerados por políticas de educação linguística adotadas durante a segunda campanha de nacionalização do ensino no Médio Vale do Itajaí, SC. Como instrumento de investigação, utilizou-se a entrevista narrativa com indivíduos teuto-brasileiros acima de 78 anos. As análises, apoiadas na Educação e na Linguística Aplicada, em diálogo com os Estudos Culturais, apontam para os movimentos de resistência do grupo teuto-brasileiro quanto à imposição de uma única língua e uma única cultura.

Palavras-chave: Identidade. Língua Alemã. Segunda Campanha. Nacionalização do Ensino.

ABSTRACT - Reflections on Language Education Policies in a Multilingual Context. The aim, in this article, is to discuss partial data from a qualitative interpretive study in order to address the language and identity conflicts generated by language education policies adopted during the second teaching nationalization campaign in the Médio Vale do Itajaí region, Santa Catarina state. The research was conducted using narrative interviews with German-Brazilian individuals over 78 years old. The analyses, based on Education and Applied Linguistics studies, in dialogue with Cultural Studies, point to resistance movements of the German-Brazilian group facing the imposition of a single language and culture.

Keywords: Identity. German Language. Second Campaign. Teaching Nationalization.

Educação \& Realidade, Porto Alegre, v. 41, n. 2, p. 491-512, abr./jun. 2016 491 http://dx.doi.org/10.1590/2175-623652092 
$\underline{\text { Reflexões sobre Políticas de Educação Linguística em Contexto Plurilíngue }}$

\section{Introdução}

"Só podia falar português naquela época da guerra". Essa fala, que abre o presente artigo, foi extraída de uma entrevista gravada com um indivíduo teuto-brasileiro ${ }^{1}$ nascido em 1928, em Santa Catarina, na região do Médio Vale do Itajaí. Ele se refere ao período histórico quando muitos descendentes de imigrantes tiveram de deixar de utilizar sua língua de herança familiar, em virtude da segunda campanha de nacionalização do ensino, em vigor durante o Estado Novo (1937-1945).

O Médio Vale do Itajaí foi colonizado predominantemente por imigrantes alemães, embora imigrantes de outros países, além de povos indígenas, também tenham contribuído para a composição do cenário intercultural da região. As justificativas do país ao incentivar a imigração no século XIX tiveram como foco central a ocupação estratégica das terras pouco povoadas do Sul a fim de elevar a produção agrícola, a substituição de mão de obra escrava e "o branqueamento da raça brasileira" (Luna, 2000, p. 81). Essa ideologia do branqueamento pregava a miscigenação para a purificação das raças, por conseguinte, havia o mito de que os negros tenderiam a desaparecer (Seyferth, 1986).

Nesse cenário, sociolinguística e sócio-historicamente complexo de minorias étnicas (Cavalcanti, 2006; 2011), duas campanhas de nacionalização do ensino determinaram políticas voltadas ao silenciamento linguístico dos imigrantes e seus descendentes no decorrer da I e da II Guerra Mundial, em Santa Catarina (Luna, 2000). A primeira delas, durante o governo estadual de Vidal Ramos, entre 1911 e 1920, ocorreu "sob o comando do professor paulista Orestes Guimarães" (Mailer, 2003, p. 39), implantando programas e reformas no sistema de ensino com fins de assimilar grupos de imigrantes. A segunda ocorreu a partir do período ditatorial do governo de Getúlio Vargas (1937-1945), mencionada anteriormente. Os efeitos dessa campanha, já de âmbito nacional, foram mais abrangentes, atingindo, além do ensino da língua alemã, toda a esfera social (Luna, 2000; Fritzen; Ewald, 2013).

Em Santa Catarina, Nereu Ramos ${ }^{2}$ foi o interventor durante o Estado Novo. Ele cumpriu "[...] à risca as determinações da campanha, baixando decretos que normatizaram a intervenção nas escolas, associações e outras instituições demarcadoras de pertencimento étnico" (Seyferth, 1997, p. 97). As ações normativas se estendiam a todas as línguas de imigração que, por razões políticas, foram tratadas como línguas estrangeiras, provocando tensões e conflitos nas populações, especialmente de origem alemã e italiana. Pelo contexto de imigração alemã em estudo, discutimos os efeitos dessa campanha apenas para os grupos teuto-brasileiros.

Neste artigo, recorte de um estudo mais abrangente ${ }^{3}$, nosso propósito é discutir os conflitos linguísticos e identitários gerados a partir das políticas nacionalistas adotadas pelo Estado Novo. O cenário em estudo abrange os municípios do Médio Vale do Itajaí, que faziam parte 
da então Colônia Blumenau, fundada em 1850 por imigrantes alemães. Essa colônia compreendia quase toda a região do Médio Vale. Hoje, essa região é formada pelos seguintes municípios: Apiúna, Ascurra, Benedito Novo, Blumenau, Botuverá, Brusque, Doutor Pedrinho, Gaspar, Guabiruba, Indaial, Pomerode, Rio dos Cedros, Rodeio e Timbó.

Para compor o corpus da pesquisa, utilizamos como instrumento de investigação a entrevista narrativa (Bauer; Gaskel, 2002), por meio da qual os sujeitos participantes do estudo, todos acima de 78 anos, puderam reconstruir sua trajetória de vida relacionada a práticas sociais de leitura e escrita em sua língua de herança. Nas discussões realizadas neste artigo, estão presentes excertos de quatro entrevistas, as quais contribuem para a compreensão de aspectos relacionados às políticas de educação linguística e seus desdobramentos que atingiram todo o convívio social no Médio Vale do Itajaí/SC. As entrevistas foram gravadas com teuto-brasileiros naturais de municípios que faziam parte da então Colônia Blumenau, nascidos entre 1916 e 1934.

A partir dessa introdução, organizamos o artigo em quatro seções. Inicialmente, discorremos sobre os conceitos de identidade e representação, com base nos Estudos Culturais. Introduzimos a próxima seção com aspectos relacionados ao contexto pesquisado e com os depoimentos dos entrevistados para refletirmos sobre os fatores que constituem a identidade étnica do grupo teuto-brasileiro, bem como os conflitos estabelecidos a partir das políticas linguísticas referentes à segunda campanha de nacionalização do ensino. Em seguida, analisamos os movimentos e formas de resistência com relação à imposição de uma identidade nacional ao grupo teuto-brasileiro. Por fim, apresentamos nossas considerações finais com o intuito de contribuir para a reconstrução da história linguística e educacional do Médio Vale do Itajaí, a partir dos atores sociais que a vivenciaram, a fim de darmos visibilidade ao cenário intercultural da região.

\section{Considerações sobre Identidade e Representação}

Consideramos, neste estudo, que as pessoas se constituem e se reconstituem por meio de processos de interação social, através das várias práticas discursivas das quais participam (Cavalcanti, 2011). Para tratarmos desses processos e práticas discursivas, discutimos os conceitos de identidade e representação com base nos Estudos Culturais, em diálogo com a Educação e Linguística Aplicada.

Discorremos sobre questões relacionadas à identidade e linguagem para analisarmos as narrativas de teuto-brasileiros que viveram o período da segunda campanha [de nacionalização do ensino], com a intenção de darmos visibilidade à educação desse grupo minoritário ou minoritarizado (Cavalcanti, 2011). Convém destacar que o termo minoritário não diz respeito a uma qualificação numérica, mas tem um senti- 
$\underline{\text { Reflexões sobre Políticas de Educação Linguística em Contexto Plurilíngue }}$

do ideológico relacionado a um grupo que fala uma língua destituída de status, invisibilizada e minoritarizada na sociedade (Cavalcanti, 2006; 2011).

Como apontam os depoimentos que seguem neste artigo, o contexto em estudo é um cenário, assim como muitos outros no país, que, ao longo da história, foi cultural e linguisticamente invisibilizado devido a políticas linguísticas que buscavam uma identidade nacional única, em especial durante o período em estudo. Embora o projeto de nação tenha se assentado na ideologia do monoculturalismo e do monolinguismo, esses cenários são interculturais, isto é, se constituem em meio a diferentes identidades culturais, sejam elas ligadas aos descendentes de imigrantes, aos índios, aos migrantes vindos de outras regiões do país.

A identidade, criada através de atos de linguagem, é produzida por meio da representação, que, "[...] como qualquer sistema de significação, [é] uma forma de atribuição de sentido. Como tal, a representação é um sistema linguístico e cultural: arbitrário, indeterminado e estreitamente ligado a relações de poder" (Silva, 2012, p. 76; 91).

Diante disso, quando discutimos identidade, nos referimos ao conjunto de características pelas quais os grupos se definem como aquilo que eles são. Dentre essas características, estão os processos de diferenciação. Para Silva (2012, p. 76), "identidade e diferença são vistas como mutuamente determinadas" e estreitamente ligadas, precisando da representação para existir, já que são resultados social e culturalmente relacionados com o outro. Assim, o processo de construção e projeção das identidades culturais e das diferenças é inacabado e ocorre sempre por meio do discurso.

As drásticas medidas resultantes das políticas de nacionalização do ensino estão diretamente conectadas às relações de poder entre grupos de diferentes identidades culturais e à projeção de uma identidade nacional única. No embate dessas relações e na disputa entre as línguas e os grupos que as falam, gerou-se a ideia de que o alemão falado pelos teuto-brasileiros é uma língua estrangeira, ou, em outros casos, uma não-língua, para usar uma expressão de Cavalcanti (2011). Por conseguinte, construíram-se, especialmente durante o Estado Novo, representações de teuto-brasileiros como inimigos da pátria, por não pertencerem a então imaginada comunidade nacional (Hall, 2005). A estigmatização dos grupos de descendentes de imigrantes está presente nos próprios dizeres dos sujeitos entrevistados, como sinaliza a Sra. Bertha, nascida em 1934, no excerto a seguir:

Excerto 01 - Sra. Bertha ${ }^{4}$

Bertha: E essa gente odiava os alemães. Também quando nós andávamos, eles passavam pela gente e chamavam a gente de quinta coluna. E, e, e... Entrevistadora: Quinta coluna por quê?

Bertha: Eu não sei. Mas porque a quinta coluna era um xingamento na época de todos os descendentes de alemães. Se bem que um outro dia um descendente de italiano me disse que eles também eram chamados de quinta coluna né. O porquê deste quinta coluna eu até hoje não sei e eu até nunca fui atrás pra saber a origem. 
Na história de Santa Catarina, observamos que a expressão quinta coluna, utilizada por "essa gente [que] odiava os alemães", era usada também para designar outras etnias. Essa expressão corresponde a representações que ainda estigmatizam os descendentes de imigrantes, como conta a Sra. Bertha, além dos alemães. As representações presentes nos discursos que circulavam no país os caracterizavam, em tempos de Guerra, como quinta coluna, possivelmente por falarem uma língua que não correspondia à identificação com a nação brasileira, mas os identificava à Alemanha, considerado país inimigo. No dicionário Houaiss (2001, p. 2363), no verbete quinta-coluna, entre outras acepções, consta: "qualquer indivíduo (nacional ou estrangeiro) que atua, dissimuladamente, em um país prestes a entrar ou já em guerra com outro, no sentido de auxiliar uma provável invasão, ou espionando e fazendo propaganda subversiva”. Além do uso de quinta-coluna como insulto aos teuto-brasileiros em situações de oralidade, seu emprego também atingiu a imprensa, em que circulavam palavras como “[...] 'traidores', 'alienígenas', 'agentes da Gestapo', 'espiões', 'sabotadores', 'perigosos', 'nazistas', ‘quistos étnicos', 'quistos raciais', etc.” (Fáveri, 2004, p. 46, grifos da autora).

Ao tratar da formação da consciência nacional, no contexto da Europa, durante as revoluções do século XIX, Berenblum (2003, p. 39) sustenta que os governos difundiram uma "identificação dos cidadãos ao Estado e a seu sistema dirigente" e utilizaram a "máquina administrativa que levantava a questão da língua - ou línguas - de comunicação dentro dos Estados”. Esses movimentos citados pela autora buscavam propagar, assim como os movimentos da segunda campanha no Brasil, a imagem de uma identidade nacional que correspondesse ao Estado-Nação, unindo os cidadãos a uma "determinada cultura como forma comum de pensar e de viver” (Berenblum, 2003, p. 32).

A identidade nacional constitui-se somente quando representada por um conjunto de significados, culturas e símbolos. É no próprio discurso que se constrói a ideia de cultura nacional, uma vez que nele se produzem sentidos que influenciam as ações e a concepção que as pessoas criam para si (Hall, 2005). As representações da identidade nacional, produzidas a partir de discursos sobre a nação, se constroem, assim, por meio de comunidades imaginadas, isto é, por meio da comunidade nação, em que o Estado "é a pátria de todos os cidadãos" (Berenblum, 2003, p. 34).

Nesse processo de construção de identidades nacionais, a língua desempenha um papel fundamental. Para cada nação, segundo Berenblum (2003), há uma língua pura que representa a identidade nacional única. No caso da nação brasileira, essa língua pura corresponde à portuguesa em sua forma padrão. Por meio da língua oficial do país, sempre se representou a existência de uma única possibilidade de identidade cultural, mantendo-se as instituições nacionais baseadas, por consequência, na ideia de uma cultura homogênea. Tal representação, 
$\underline{\text { Reflexões sobre Políticas de Educação Linguística em Contexto Plurilíngue }}$

em termos nacionais, nos leva ao mito de uma identidade unificada, o que provocou o fechamento, a partir do período do Estado Novo, das instituições que divulgavam os valores e a língua dos sujeitos teuto-brasileiros no Vale do Itajaí, como discutimos nas próximas seções.

\section{As Identidades no Contexto Educacional em Estudo}

Como mencionado anteriormente, o Brasil incentivou a vinda de imigrantes europeus à região Sul do país. Todavia, o sistema escolar que existia nos Estados do Sul ainda era altamente deficitário: havia poucas escolas públicas funcionando em todo o território nacional. Por isso, assim que chegaram, os imigrantes alemães começaram a organizar escolas étnicas, mantidas com o apoio das respectivas lideranças religiosas (Fáveri, 2004; Luna, 2000).

Havia diversas razões pelas quais os imigrantes alemães possuíam um interesse expressivo, segundo Bezerra (2007, p. 44), pela escola. Destacamos duas dessas razões: primeiro, os imigrantes traziam consigo um conhecimento escolar, "já que a Alemanha foi uma das precursoras da instrução pública moderna gestada desde os primórdios da Reforma Protestante"; e segundo, havia a necessidade de "integração à sociedade brasileira".

Luna (2000) aponta que, em Santa Catarina, no início do século XX, 40\% das escolas eram privadas, fundadas por imigrantes alemães. Especialmente por motivos religiosos e por trazer aspectos da cultura do país de origem, era indiscutível o fato de que a língua alemã seria o idioma de instrução e de ensino nas escolas dos imigrantes. Apesar disso, sempre houve uma preocupação com relação ao ensino do português, já que, para o grupo teuto-brasileiro, a cidadania e a etnia eram questões fundamentais no processo escolar. Ao mesmo tempo em que o grupo se considerava de nacionalidade brasileira, acreditava "no direito de manter a língua e peculiaridades étnicas de origem” (Kreutz, 2003, p. 136). A Sra. Bertha, no excerto a seguir, recupera aspectos do processo de formação das escolas teuto-brasileiras da região onde vive:

Excerto 02 - Sra. Bertha

Bertha: [...] e a cultura alemã, quem vinha da Alemanha, vinha de um país desenvolvido onde a coisa mais importante eram os filhos na escola, na igreja. Eram os dois é, como é que é? Os dois pilares do ser humano pro alemão. Então, que que eles traziam? A bíblia e o cancioneiro alemão. Todos eles trouxeram isso. Só que chegando aqui, não tinha professor. [...] os professores vinham da Alemanha, eles faziam um curso na Alemanha se preparando pra vir pro Brasil. Um curso de português. Mas ahn, ensinado, lá, não por brasileiros, também por alemães. Então, minha tia é que contava que ela aprendeu o português, porque o português era uma matéria dentro do programa da escola alemã. História, Geografia, tudo isso eles aprendiam em alemão, mas o português era uma matéria. [...] ATÉ QUE na nacionalização, os professores que estavam aqui eram tudo professores da Alemanha [...]

496 Educação \& Realidade, Porto Alegre, v. 41, n. 2, p. 491-512, abr./jun. 2016. 
A partir das histórias narradas pelos teuto-brasileiros, como nesse depoimento da Sra. Bertha, ressaltamos a preocupação com a língua portuguesa nas escolas étnicas. Kreutz (2003) sustenta, quanto ao ensino da língua oficial do Brasil, que houve o investimento em edições e reedições de materiais didáticos para a sua instrução, alguns deles produzidos pela Associação de Professores Teuto-Brasileiros de Santa Catarina, em Blumenau.

Apesar da tentativa em incluir efetivamente a língua portuguesa no currículo das escolas teuto-brasileiras, até a década de 1930, de acordo com Kreutz (2003), o ensino do português foi considerado, pelo governo, insatisfatório. Isso porque havia poucos professores que soubessem falar a língua oficial do Brasil e, como a própria Sra. Bertha relata, aqueles professores que a aprendiam, o faziam com outros alemães. Assim, a língua portuguesa passou a ser ensinada com dificuldade às crianças que tinham, muitas vezes, contato apenas com a língua alemã fora da escola, ainda que nascidas no Brasil.

Diante dessa configuração que se foi estabelecendo nas regiões das antigas colônias, o governo Vargas instituiu a campanha de nacionalização do ensino. Nessa campanha, criaram-se decretos e leis que coibiram o uso de línguas ditas estrangeiras, na verdade, línguas de imigração, incumbindo aos agentes da nacionalização a destruição do material didático das escolas étnicas (Kreutz, 2003). Segundo Luna (2000, p. 20), o governo brasileiro justificou a intervenção nessas escolas por meio da suposição de que seus alunos "não recebiam o ensino da língua portuguesa. Essas escolas passaram a ser, assim, vistas como desnacionalizadoras, vindo a sua maioria a ser impedida de funcionamento".

Junto à proibição do ensino da língua alemã, houve também a coibição de publicação de livros e demais materiais escritos em língua estrangeira. No próprio Decreto-Lei no 406, de 04 de maio de 1938 (Brasil, 1938), já é possível constatar as medidas tomadas para impor a cultura e língua nacional aos diferentes grupos étnicos. Nesse decreto, no capítulo XVI, Art. 85, estabelecia-se nos parágrafos primeiro, segundo e terceiro que as escolas deveriam ser regidas por brasileiros natos, as línguas estrangeiras não poderiam ser ensinadas a menores de 14 anos e os livros destinados ao ensino primário teriam de ser escritos em língua portuguesa. O Art. 94 desse mesmo Decreto-Lei estabelecia, ainda, que nas zonas rurais do país não seria permitida a publicação de livros, revistas ou jornais em língua estrangeira.

A seguir, apresentamos um excerto do depoimento da Sra. Walburga, nascida em 1928, que traz à memória o alcance das ações que se desdobraram a partir desse decreto.

Excerto 03 - Sra. Walburga

Walburga: [...] eu conheço os livros, uns de História. Mas a grande maioria foi vendido pra papelão quando a, isso eu não me lembro agora em 
$\underline{\text { Reflexões sobre Políticas de Educação Linguística em Contexto Plurilíngue }}$

que ano que foi, que foi proibida a língua alemã. É que tinha guerra da Alemanha, não com o Brasil, mas infelizmente o Brasil também mandou soldados né, pra lá né, e então foi proibido. Então eles até vinham nas casas ver quem é que tinha alguns livros em alemão. Então a gente escondeu. ((risos)) Pois é, eu me lembro ainda os melhores que nós tínhamos, nós escondemos dentro de um, um, a gente diz como é que é? Colmeia, de abelha. E depois quando nós fomos ver, depois de três meses, as formigas assim bem grandes, tinham feito tudo um ninho ali e roído tudo. ((risos)) Praticamente os livros todos.

A história individual relatada pela Sra. Walburga vai reconstituindo fios da história coletiva da região. Essa senhora coloca-se em um cenário maior, em um período de Guerra, quando no Brasil as proibições vieram com a ação militar que afetou muitos descendentes de imigrantes.

Por meio do depoimento da Sra. Walburga e outros entrevistados, é possível constatar que as ações de destruir livros não se restringiram apenas às escolas étnicas, mas a todos os locais onde ainda houvesse material escrito na língua de imigração, além dos didáticos. Quando ela conta que "eles até vinham nas casas ver quem é que tinha alguns livros em alemão”, se refere aos agentes da nacionalização (Kreutz, 2003), o que a faz complementar: "então a gente escondeu", isto é, utilizaram estratégias de resistências às ações coercivas do governo getulista.

Além da família da Sra. Walburga, o valor atribuído à leitura e à escrita levou outras famílias teuto-brasileiras a utilizarem estratégias para salvarem os artefatos culturais (Bartlett, 2007) ligados à língua alemã. $\mathrm{O}$ acesso à cultura letrada e a bens culturais que dela fazem parte é essencial para o processo de constituição leitora (Sousa, 2010). No caso de muitos sujeitos do contexto em estudo, esse processo de constituição se deu na língua de herança, por isso os entrevistados produzem, em seus enunciados, valores em relação aos bens culturais na língua alemã - no excerto acima, os livros da família da Sra. Walburga.

O livro é um bem cultural que representa valor, segundo Sousa (2010, p. 05), por estar presente nas vidas das pessoas "desde cedo, com objetivo de disseminação da cultura”. Por esse valor, a Sra. Walburga relata a decisão em esconder os livros dentro de uma colmeia de abelhas. Outros depoimentos aparecem nas demais entrevistas sobre o ato de guardar materiais escritos na língua de imigração.

Os demais bens culturais do grupo teuto-brasileiro, com relação ao período anterior à campanha, divulgavam e reafirmavam seus valores étnicos, ligados à língua e identidade. Era perfeitamente comum utilizar a língua de imigração em diferentes esferas sociais de prestígio em Santa Catarina, inclusive por meio da linguagem escrita. Com a própria intensificação da produção literária no Sul do Brasil, os escritores teuto-brasileiros nascidos em regiões coloniais de Santa Catarina viam a necessidade de produzir uma literatura nesse Estado. O escritor Johann Friedrich Georg Ernest Niemeyer, filho de imigrantes alemães, 
no seu estudo Teutonen Literatur, ressaltava a importância de haver a literatura no contexto brasileiro, que não fosse literatura alemã, "mas teuto-brasileira, escrita em língua alemã” (apud Seyferth, 2004, p. 193).

A língua alemã parece ter adquirido espaço maior na sociedade por meio de práticas letradas, uma vez que, além da fundação de escolas de pertencimento étnico, fundaram-se também livrarias, editoras e jornais para a publicação dos materiais escritos em alemão. Quando a língua de imigração e os grupos que a falavam tornaram-se visíveis com suas práticas de leitura e de escrita, passaram a ser considerados como um problema que abalava o ideal monolíngue brasileiro.

Para que a campanha fosse bem-sucedida com relação aos objetivos de assimilação das diferenças, a presença de agentes da nacionalização, que confiscavam os materiais escritos em alemão nas casas das famílias, conforme relatos dos entrevistados, foi fundamental. Justamente por registrarem a presença da cultura teuto-brasileira na região, os materiais escritos em alemão eram destruídos, por vezes queimados em praça pública. A coesão nacional deveria estar assentada em uma identidade fixa e única, refletindo a ideia de um país culturalmente homogêneo. Nesse sentido, a seguir, apresentamos um excerto da entrevista com o Sr. Ulmer, nascido em 1928, cujo relato sinaliza uma tentativa de apagamento de diferentes identidades culturais por meio da nacionalização do ensino, na falsa ideia de unificação da identidade nacional:

\section{Excerto 04-Sr. Ulmer}

Entrevistadora: E isso é alfabetização em português, no caso?

Ulmer: Não, primeiro era alemão, porque como é que vai ensinar o abc? Depois que sabia o abc, logo tinha que aprender o português né [...] nós aprendíamos o verbo em alemão, depois em português [...].

Entrevistadora: E essa escola que o senhor contou, que falou primeiro, era particular né, ela era da igreja?

Ulmer: É, não, era da, era da / porque tinha duas escolas, a luterana e a católica. Nós era professor Roediger e a católica é o padre né. Até que passou a estadual a nossa, aí os outros também vieram pra nossa, aí tinha uma só. Então tinha sempre uma tabuleta bem grande, estava escrito bem grande escola particular, na entrada. Mas um dia chegamos de manhã cedo, foi logo depois de ano novo, dia dois de janeiro, que as aulas já começavam em dois de janeiro né, e não era mais particular, estava escrito bem grande escola estadual, não existia mais. Quando entramos na escola, aí nós vimos na parede duas fotos bem grandes, Nereu Ramos e Getúlio Vargas, governador e presidente. Daí o professor / cantamos o hino nacional como sempre né, ele fez a chamada, aí ele falou: ó de hoje em diante as coisas mudam, a casa vai ser bem mais dura, porque a escola não é mais o pai de vocês que paga que mandam, é o governo do estado que manda $[. .$.

Observamos, no enunciado do Sr. Ulmer, duas fases distintas com relação ao ensino e à educação linguística nas escolas étnicas. A primeira corresponde ao período quando as instituições educacionais ainda 
$\underline{\text { Reflexões sobre Políticas de Educação Linguística em Contexto Plurilíngue }}$

mantinham a língua de imigração e, a segunda, quando a maioria delas foi fechada ou tomada pelo governo para tornarem-se escolas monolíngues. Luna (2000) salienta que quando o ensino era fornecido em duas línguas, era comum que a alfabetização do aluno ocorresse inicialmente em alemão, primeira língua das crianças, para depois haver o ensino da língua portuguesa, assim como relata o Sr. Ulmer quanto à sua experiência escolar.

Como vínhamos discutindo, quando os imigrantes se instalaram no Sul do Brasil, havia poucas escolas. Conforme Luna (2000, p. 116), "Blumenau, até 1883, contava apenas com duas escolas públicas. A educação das crianças continuava confiada, então, às escolas particulares, que à época já eram noventa [em Blumenau]”. O Sr. Ulmer, que estudou em uma dessas escolas teuto-brasileiras, ligadas à Igreja de Confissão Evangélica Luterana, aponta em seu depoimento para a prática dessas instituições em alfabetizar primeiro na língua materna das crianças para depois investir no ensino da língua oficial do Brasil.

O próprio Hermann Blumenau, fundador da Colônia Blumenau, manifestava sua preocupação em encontrar professores que ensinassem o português. Em um de seus Relatórios ao Governo Imperial, de 1856, destacou: "A frequência da escola de primeiras letras, cujo professor, colono naturalizado e pago pela província, ensina em ambas as línguas simultaneamente como é necessário, teve regular andamento e progride" (Relatório de 1856, p. 4 apud Luna, 2000, p. 121). Nas escolas teuto-brasileiras, portanto, as línguas alemã e portuguesa eram consideradas fundamentais nas práticas escolares, a primeira por ser a língua do país de origem dos imigrantes e a outra por representar a língua da nação brasileira (Kreutz, 2003).

O Sr. Ulmer também reconstrói episódios significativos referentes às medidas tomadas em Santa Catarina durante o período em estudo. Ele descreve que a escola "não era mais particular, estava escrito bem grande escola estadual”, portanto, subsidiada pelos cofres públicos. Essas escolas particulares eram as escolas comunitárias e religiosas, mantidas pelas famílias e entidades ligadas à igreja.

Até o período de nacionalização do ensino, os grupos teuto-brasileiros tinham autonomia para decidir questões relacionadas às escolas comunitárias e religiosas, como a língua de ensino. Havia, inclusive, sociedades escolares e uma associação, a Associação das Escolas Alemãs para Santa Catarina (Deutscher Schulverein für Santa Catarina, como era chamada), que publicava mensalmente um boletim informativo (Mitteilungen), dirigido aos professores, contendo orientações pedagógicas e outros assuntos de interesse dos docentes (Silva, 1972). Quando a escola passou a pertencer ao Estado, por consequência, coube ao governo decidir que língua e cultura seriam difundidas nela. Nesse depoimento do Sr. Ulmer, depreendemos as disputas de poder entre as diferentes identidades culturais presentes na região.

500 Educação \& Realidade, Porto Alegre, v. 41, n. 2, p. 491-512, abr./jun. 2016. 
As famílias teuto-brasileiras ficaram destituídas de poder para representar os interesses do seu grupo étnico. Como discutido anteriormente, por meio da representação, as identidades adquirem sentido, logo, "quem tem o poder de representar tem o poder de definir e determinar a identidade" (Silva, 2012, p. 91). No enunciado do Sr. Ulmer, vemos que, por meio de políticas de educação linguística monoculturais, houve a tentativa de apagar as diferenças étnicas, disseminando uma identidade nacional única. Vale lembrar que a representação de uma identidade nacional unificada se constrói por meio de uma ideia de nação, de uma comunidade imaginada (Berenblum, 2003). Assim, no momento em que a escola onde o Sr. Ulmer estudava passou a ser estadual, foram afixados nas paredes os retratos do governador e do presidente, como símbolos de poder e os alunos passaram a uma nova rotina escolar.

Em virtude da nacionalização do ensino, as medidas proibitivas foram impostas ao Sr. Ulmer e, como ele mesmo menciona, a outros. Esses outros a quem o Sr. Ulmer se refere são teuto-brasileiros que estudavam em uma escola da Igreja Católica, mas que passaram para a mesma instituição de ensino com a campanha: "até que passou a estadual a nossa, aí os outros também vieram pra nossa".

Essas imposições feitas aos grupos étnicos ajudaram a reafirmar a desigualdade de poder entre as diferentes identidades culturais. É preciso ressaltar que essas diferenças, a existência de um outro, nos Estudos Culturais, são essenciais para a formação da identidade (Silva, 2012). Dessa forma, por corresponder também a uma identidade cultural, a identidade étnica se constrói pelo diferente. Falar uma língua de herança e ser um brasileiro descendente de imigrantes evoca uma identidade étnico-linguística (Fritzen, 2007) que se difere de outras identidades culturais (Seyferth, 1997). Como sustenta Rajagopalan (2003, p. 71) "[...] as identidades estão, todas elas, em permanente estado de transformação, de ebulição. [...] A única forma de definir uma identidade é em oposição a outras identidades em jogo".

É nesse jogo de identidades que se confrontavam dois extremos de diferenças: o brasileiro em oposição àqueles descendentes de imigrantes que, embora nascidos no Brasil, foram tratados como estrangeiros. Ainda que a campanha de nacionalização tenha tido como meta o apagamento das diferenças, elas sempre existiram e existirão, isto é, a diferença estava e ainda está presente no contexto em estudo, gerando um lugar de interculturalidades, uma vez que todas as ações humanas, as representações e os valores são perpassados pela cultura (Maher, 2007b; Hall, 1997).

Nos depoimentos ora apresentados, emergem conflitos a respeito dessas diferenças entre as identidades culturais da região. São reflexos das distintas identidades culturais e suas representações propagadas nos discursos hegemônicos, inclusive governamentais. Em suma, tais 
$\underline{\text { Reflexões sobre Políticas de Educação Linguística em Contexto Plurilíngue }}$

conflitos foram produzidos pelas complexas relações de poder estabelecidas com a coibição das línguas de imigração em território nacional. Se, por um lado, a língua alemã e seus falantes, até a década de 1940, desfrutavam de um certo poder local, materializado pelos discursos da imprensa, pela presença da língua na literatura e na escola, a partir da campanha em questão, suas manifestações culturais foram silenciadas.

Para seguirmos a discussão, na próxima seção, analisamos a resistência à imposição de uma língua e uma cultura nacionais aos grupos teuto-brasileiros.

\section{Atitudes de Resistência às Políticas Monoculturais}

Como já afirmado, um dos marcos da proibição do uso de línguas de imigração no Brasil corresponde justamente às políticas linguísticas adotadas pelo governo de Getúlio Vargas. Na seção anterior, discutimos a concepção de identidade, a constituição étnico-linguística do grupo teuto-brasileiro e a sobreposição de uma identidade nacional, durante o Estado Novo, em detrimento de outras identidades culturais.

Diante da imposição de uma língua e uma cultura nacional, algumas famílias manifestaram atitudes de resistência para continuar a falar a língua de imigração e a realizar práticas mediadas pela linguagem escrita em alemão. Trazemos, assim, a fala do Sr. Ulmer, que abriu o presente artigo, sobre questões relacionadas ao pertencimento étnico e a medidas nacionalizadoras no âmbito do ensino, para discutirmos os movimentos de resistência do grupo:

\section{Excerto 05 - Sr. Ulmer}

Ulmer: É, essa foi a época da guerra já. Então só podia falar português naquela época da guerra né. Mas nós falávamos alemão escondido também né. E ali já era bem mais, a gente foi aprendendo, como hoje assim né, mas dá pra se virar né. Então o meu irmão, ele aprendeu mais, como pegou escola mais em português do que eu. Meu irmão mais novo né. [...] aí quando chegou o primeiro ano, depois que começou aí veio o dia sete de setembro. Uma semana antes do dia sete de setembro, o professor disse: essa semana nós temos aula só até no recreio e depois nós vamos aprender a marchar. Porque nesse ano nós temos que marchar no dia sete de setembro. Não é desfile, é marcha. [...] e tinha vindo o doutor Theobaldo Costa Jamundá, ele veio pro batalhão, e a prefeitura contratou ele pra difundir o idioma português né [...]

Uma das medidas tomadas a fim de assimilar as diferenças em uma identidade nacional monocultural, narrada pelo Sr. Ulmer, se refere à vinda a Blumenau de Theobaldo Costa Jamundá. Nascido no nordeste do Brasil, conforme Seyferth (1997), Jamundá foi recrutado, em 1939, no 32ํㅡㄹ Batalhão de Caçadores em Blumenau, com a finalidade de promover a integração nacional em Santa Catarina. O grupo teuto-brasileiro, no entanto, por questões relacionadas à identidade étnica, realizou movimentos de resistência ao continuar falando a língua ale- 
mã. Como o próprio Sr. Ulmer relata, "só podia falar português naquela época da guerra né. Mas nós falávamos alemão escondido também”.

Os efeitos do período de nacionalização estão presentes no depoimento do Sr. Ulmer, quando ele narra o silenciamento linguístico sofrido pelo grupo teuto-brasileiro. Outras marcas da campanha também estão ligadas aos símbolos nacionais, impostos através de atividades cívicas. Depreendemos, quando o senhor entrevistado relata sobre o período de Guerra, que atividades como "aprender a marchar", ou até mesmo a cantar o "hino" (Excerto 04), aconteceram na região, em especial, durante a implementação da campanha.

Tais atividades, nas escolas étnicas, também se tornaram uma forma de difundir tradições e símbolos nacionais que despertassem nos alunos o sentimento patriótico com relação ao Brasil. Como sustenta Berenblum (2003, p. 39), a finalidade dos símbolos difundidos nas escolas é possibilitar "o surgimento de sentimentos de adesão e lealdade" à própria nação. A escola, assim, serviu a um objetivo específico: reafirmar os valores de um grupo cultural. Em cada período presente nas narrativas dos sujeitos, a escola, por questões políticas, é regida por um grupo diferente: primeiramente pelos próprios grupos teuto-brasileiros e a partir do período do Estado Novo pelo governo.

Para os alunos de instituições de ensino como esta onde o Sr. Ulmer estudou, a identificação com o imaginário de nação implicaria adentrar em uma comunidade imaginada (Hall, 2005; Berenblum, 2003) homogênea. Hall (2005, p. 50) postula que as "culturas nacionais são compostas não apenas de instituições culturais, mas também de símbolos e representações". Dessa forma, os símbolos ou artefatos culturais também fazem parte da formação de uma identidade. Segundo Bartlett (2007), as pessoas, além de se constituírem, também participam de eventos e práticas de letramento em meio a discursos e artefatos culturais, estes últimos compreendidos como objetos ou símbolos que podem ou não assumir um aspecto material, produzidos socialmente e construídos culturalmente.

Os símbolos, na perspectiva enunciativa do Círculo de Bakhtin (2004), são signos dialogicamente construídos, e por isso considerados plurivalentes. Entretanto, como afirma Bakhtin (2004), as classes dominantes, através da ideologia oficial, sempre tentaram tornar o signo monovalente. "Todo signo é ideológico; a ideologia é um reflexo das estruturas sociais; assim, toda modificação da ideologia encadeia uma modificação da língua" (Yaguello, 2004, p. 16).

As ideologias aparecem através de símbolos nos dizeres dos sujeitos entrevistados. Dessa forma, o hino nacional, a marcha em comemoração ao dia sete de setembro e a língua portuguesa são símbolos que foram se construindo nas escolas para representar a identidade nacional do Brasil. 
$\underline{\text { Reflexões sobre Políticas de Educação Linguística em Contexto Plurilíngue }}$

Vale ressaltar que, embora os entrevistados tenham continuado a utilizar a língua alemã, deixando de cumprir com decretos e leis da época, não constatamos atitudes de recusa quanto à realização de atividades cívicas, provavelmente por participarem do sentimento de cidadania brasileira. Contudo, o Sr. Ulmer e demais entrevistados conflitam com a imposição da identidade nacional unificada, que permite apenas o sentimento de adesão à nação brasileira, impondo a assimilação cultural. Ao sustentar a extensa discussão sobre identidade na teoria social, Hall (2005, p. 07) afirma que "[...] as velhas identidades, que por tanto tempo estabilizaram o mundo social, estão em declínio, fazendo surgir novas identidades e fragmentando o indivíduo moderno, até aqui visto como um sujeito unificado". É nesse sentido que a ideia de identidade nacional unificada por meio de proibições e imposições torna-se mera fantasia.

A imposição da língua portuguesa sobre a língua alemã é, na verdade, a imposição de uma identidade nacional sobre várias outras identidades culturais. As medidas tomadas durante o Estado Novo ajudaram a propagar o discurso de que no Brasil se fala uma língua apenas e se tem uma cultura, deixando marcas ainda hoje sobre grupos minoritários, como os teuto-brasileiros. Tais marcas se referem aos sentimentos de medo, aos ressentimentos dos falantes do alemão, à perda linguística sofrida nas gerações seguintes e, ainda, ao preconceito vinculado a um grupo cuja língua de herança, muitas vezes, não é vista como uma língua.

O reconhecimento da existência de outras línguas implicaria considerar o Brasil como um país multicultural e plurilinguístico, o que prejudicaria a imagem de nação unificada que se tentou difundir durante os períodos de guerra.

Embora o governo tenha produzido uma imagem de nação e imposto uma língua oficial para representar a identidade nacional, os grupos teuto-brasileiros resistiram a essa imposição. Esses movimentos de resistência são evidenciados nos dizeres dos entrevistados quando a Sra. Walburga relata que a família escondeu os livros escritos em alemão (Excerto 02) e quando o Sr. Ulmer conta que continuou a utilizar a língua de imigração como língua de interação, ainda que escondido, ao lado do português. Suas atitudes estão em conexão com a própria constituição do teuto-brasileiro, uma vez que constroem sua identidade tendo o Brasil como a pátria e partilhando dos aspectos culturais ligados à língua alemã. Como explica Mailer (2003, p. 20), os descentes de imigrantes não estavam mais ligados ao Estado alemão e sua pátria era o Brasil, pois no "imaginário teuto-brasileiro era perfeitamente possível ser cidadão brasileiro e ao mesmo tempo pertencer à nação alemã". Esse sentimento de pertencimento levou os entrevistados a manterem também os símbolos ligados à sua cultura, como mostra a Sra. Bertha, nascida em 1934, no próximo excerto de entrevista: 


\section{Excerto 06 - Sra. Bertha}

Bertha: [...] minha vó, mãe da minha mãe, esteve em Berlim, nas olimpíadas de mil novecentos e trinta e seis. E aí Hitler estava no auge, na época, e aí este sino aqui foi, era o símbolo da / das olimpíadas. Vê aqui as argolas das olimpíadas e o símbolo da Alemanha. Ó, mil novecentos e trinta e seis, décima primeira olimpíada/Spiele Berlin. [...] a minha vó trouxe um e deu de presente para mamãe e esse está na casa da minha irmã. E aí eu comentei com um amigo meu da Alemanha [...] e aí ele conseguiu esse aqui. Inclusive ele está com o número do leilão aqui dentro. [...] e aqui, aqui embaixo diz: ich rufe die Jugend der Welt. Eu chamo a juventude do mundo. Então há a suástica para a décima primeira olímpiada Spiele in Berlin, mil novecentos e trinta e seis [...]

Figura 01 - Sino, Artefato Cultural da Sra. Bertha

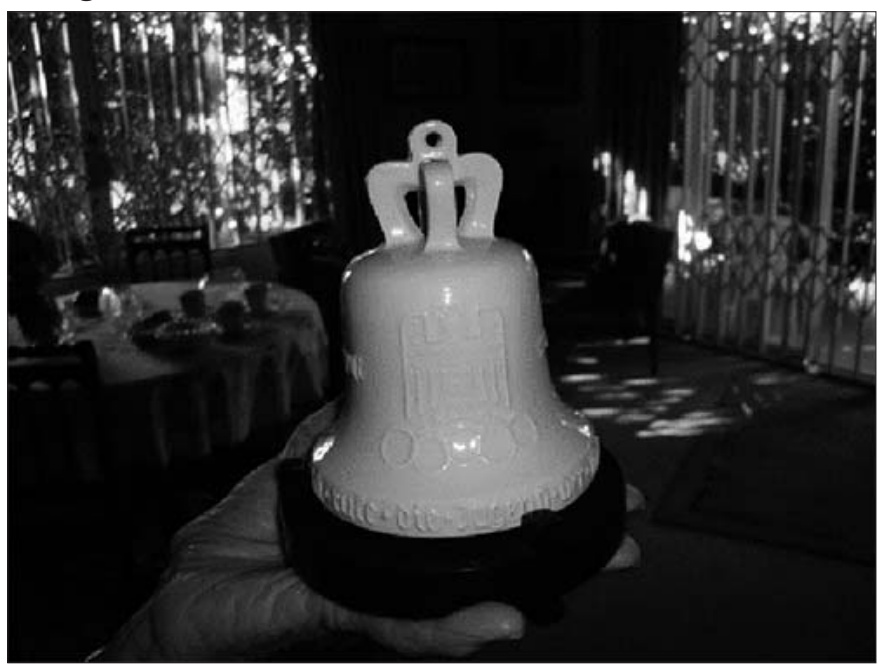

Fonte: Fotografia tirada para a pesquisa (Ewald, 2014).

Para a Sra. Bertha, ter um símbolo ligado à nação alemã, presente no excerto e na imagem acima, evoca sentidos que fortalecem o vínculo com seus antepassados alemães, como a avó. Guardar o sino das olimpíadas de Berlim é uma maneira encontrada pela Sra. Bertha de participar da cultura e língua alemã, relacionadas ao país de origem de seus próprios familiares. São símbolos, artefatos culturais como esses, presentes na história, cultura e língua dos teuto-brasileiros que contribuíram para representar-lhes, através do discurso hegemônico, como estrangeiros, nazistas, ou "quinta coluna" (Excerto 01).

Com base nos Novos Estudos do Letramento, nas teorias sócio-históricas da formação da identidade e nas teorias da prática de interação da linguagem, Bartlett (2007, p. 52, grifo no original) argumenta que “[...] 'tornar-se letrado' exige um trabalho de identidade crítica inter e intrapessoal realizado por meio do engajamento com artefatos cultu-

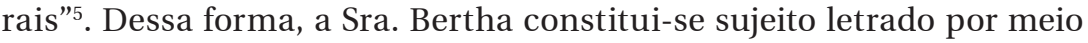


$\underline{\text { Reflexões sobre Políticas de Educação Linguística em Contexto Plurilíngue }}$

de alguns artefatos culturais, como o sino ligado ao país de origem da sua língua de herança.

Assim como a Sra. Bertha, muitos descendentes de imigrantes ainda partilham sentimentos de pertencimento à cultura alemã, marcados principalmente pelo uso da língua de imigração. É justamente por esse sentimento que houve a resistência com relação à imposição de uma identidade nacional unificada. Inferimos por meio dos depoimentos dos sujeitos participantes do estudo, em diálogo com os Estudos Culturais, que a construção da identidade, além de se dar pela diferença, está vinculada à história, à língua e à cultura. Por meio dessa constituição, ocorrem os movimentos de resistência dos teuto-brasileiros às medidas implementadas durante o governo Vargas, como sinaliza o Sr. Bernardo no próximo excerto:

Excerto 07 - Sr. Bernardo

Bernardo: O blumenauense sofreu muito, muito. Ainda hoje se comenta nos jornais essa passagem né, este fato. Como nós sofremos em Blumenau, como nós sofremos por causa dessa língua. Mas fomos duros, porque você vê, ainda hoje sentam-se grupos inteiros juntos assim, só falam alemão. Mas é pouco.

Apesar de as políticas terem coibido o uso da língua de imigração, como evidencia o Sr. Bernardo, e terem trazido sofrimentos para os teuto-brasileiros, esses indivíduos se mostraram duros e continuaram a falar alemão escondido (Excerto 05), influenciados por sua história e cultura. O próprio termo utilizado pelo Sr. Bernardo traz o sentido, em seu enunciado, de resistência. Compreendemos que, ao tornarem-se duros, os teuto-brasileiros criaram uma proteção que os permitia se identificarem com a cultura, história e língua de seus antepassados. Em outras palavras, os teuto-brasileiros resistiram às políticas linguísticas que determinavam o português como única língua de interação social, e seguiram produzindo e reafirmando suas diferentes identidades culturais. Por conseguinte, "hoje sentam-se grupos inteiros juntos" e usam a língua alemã como língua de interação. É justamente por essa atitude de resistência que a língua alemã permaneceu nas histórias de letramentos do grupo teuto-brasileiro do Médio Vale do Itajaí, SC (Fritzen; Ewald, 2013).

Diante das identidades culturais que continuam a ser construídas, é possível afirmar que as diferenças seguem a conviver e a se tensionar no Médio Vale do Itajaí, como em todo o país. Por isso, problematizamos, neste artigo, o mito da pureza e homogeneidade propagado com as políticas da campanha de nacionalização do ensino. Esse mito, como vimos, exclui as diferenças entre as pessoas de um mesmo país, na tentativa de unificá-las numa identidade cultural única. Como postula Hall (2005), a identidade nacional, que representa a lealdade, união e identificação simbólica, pode servir como uma estrutura de poder cultural.

506 Educação \& Realidade, Porto Alegre, v. 41, n. 2, p. 491-512, abr./jun. 2016. 
Nossa proposta, diante das culturas nacionais, é pensá-las não apenas como unificadas, isto é, não impor a existência de apenas uma identidade que represente o Brasil em meio a inúmeras culturas que convivem no país. Isso implica considerar, em termos de Educação, que o contexto de ensino não é apenas "uma justaposição de culturas", mas um lugar de interculturalidades, conforme Maher (2007a, p. 89), onde há diferentes identidades culturais que se modificam e se influenciam continuamente. Nesse sentido, alertamos para a necessidade de se buscar aprofundar conhecimentos sobre aspectos históricos e políticos de contextos como este abordado neste artigo, para podermos compreender os valores culturais atribuídos a práticas sociais de diferentes grupos que tomam lugar na escola.

\section{Considerações Finais}

Procuramos, neste artigo, discutir os conflitos linguísticos e identitários gerados por medidas coercitivas adotadas durante a segunda campanha (a partir de 1937). Para tanto, à luz dos Estudos Culturais, em diálogo com a Linguística Aplicada, analisamos os dizeres de teuto-brasileiros a respeito de parte da história linguística do Médio Vale do Itajaí, a fim de darmos visibilidade ao cenário multicultural e plurilinguístico da região.

Com relação às medidas tomadas durante a campanha, tanto pelo governo quanto pela sociedade, retomamos o relato da Sra. Bertha sobre o termo quinta coluna, utilizado para denominar membros do grupo teuto-brasileiro, justamente por trazer a representação negativa quanto à língua e identidade que circulava no discurso hegemônico. No depoimento do Sr. Ulmer, evidenciamos os símbolos impostos nas escolas com o fim de legitimar a identidade nacional, embora histórias como da Sra. Walburga e do Sr. Bernardo apontem para os movimentos de resistência às imposições de uma única língua e cultura. Tais resistências se materializam nos discursos da Sra. Walburga ao relatar que a família escondeu os bens culturais ligados à língua de imigração; e do Sr. Bernardo, ao contar que os teuto-brasileiros se mostraram duros e continuaram a falar a língua alemã.

Cada história individual nos leva a compreender a história coletiva da região do Médio Vale do Itajaí, campo de estudo, emergindo conflitos e relações de poder entre os grupos étnicos e os interesses do Estado. Os discursos governamentais, através da ideologia oficial (Bakhtin, 2004), durante a segunda campanha de nacionalização do ensino, representaram a identidade nacional, propagando, por meio da proibição das línguas de imigração, a ideia de homogeneidade nacional. Embora as leis previssem punições aos que utilizassem as línguas ditas estrangeiras, o grupo teuto-brasileiro buscou por estratégias para salvar alguns bens culturais que tivessem conexão com sua língua de imigração, mas, acima de tudo, continuou falando essa língua. 
$\underline{\text { Reflexões sobre Políticas de Educação Linguística em Contexto Plurilíngue }}$

As entrevistas nos levam a inferir que esse grupo partilha sentimentos de pertencimento à cultura e à língua alemã. Tais sentimentos impediram a adesão ao imaginário de identidade nacional difundido no Estado Novo, uma vez que a língua, a história e a cultura são essenciais para o processo de construção e projeção, sempre em movimento, das identidades culturais.

Os conflitos e ressentimentos gerados pela campanha são hoje reconstruídos nas memórias desses sujeitos e estão marcados nas histórias dos grupos teuto-brasileiros. O silenciamento imposto a esses grupos e outros grupos étnicos se reflete, por consequência, nas novas gerações que ingressam nas escolas. Nem sempre a instituição escolar considera os saberes locais dessas novas gerações que ainda aprendem a falar alemão em casa (quando aprendem). Assim, língua alemã, como língua de imigração, utilizada ao lado do português, ainda é, não raro, invisibilizada no contexto educacional (Fritzen; Ewald, 2011).

Ainda que, por meio de políticas linguísticas recentes, línguas de imigração, como o alemão e o italiano, estejam entrando em alguns currículos de sistemas de ensino em municípios do Médio Vale do Itajaí, SC (Maas, 2010; Spiess, 2014; Lorenzi, 2014), não há garantia de que as línguas de herança, adquiridas na esfera familiar, sejam reconhecidas e valorizadas na educação formal. O bilinguismo neste cenário, muitas vezes, ainda é visto como um problema a ser erradicado na escola.

Em consonância com Maher (2007b), Candau (2012) e Cavalcanti (2013), entendemos que um projeto educativo voltado para uma abordagem intercultural e plurilinguística carece do conhecimento e reconhecimento das diferenças, de sua problematização e de ações efetivas, abertas para o difícil diálogo entre culturas. Daí a necessidade de mais investimento em pesquisas, sua socialização e divulgação em diferentes esferas, não somente a acadêmica. O debate em torno da revisão e adoção de políticas de educação linguística, que considerem as relações entre identidade e diferença, questões políticas e de poder que subjazem a qualquer proposta educacional, precisa ganhar espaço nas agendas dos cursos de formação inicial e continuada de professores e da gestão das políticas linguísticas, tendo em vista os desafios e potencialidades do mundo contemporâneo.

Recebido em 02 de dezembro de 2014 Aprovado em 11 de fevereiro de 2016

\section{Notas}

1 A expressão 'teuto-brasileiro' é atribuída a pessoas descendentes de alemães que ainda mantêm a língua de herança e que fazem parte da terceira ou quarta geração no Brasil. Definir o grupo teuto-brasileiro é complexo, pois pode acontecer de nem todos os incluídos na categoria se identificarem necessariamente de tal maneira. Entretanto, sentimos a necessidade, ao longo da pesquisa, de atribuir uma denominação a respeito da identidade étnico-linguística dos

508 Educação \& Realidade, Porto Alegre, v. 41, n. 2, p. 491-512, abr./jun. 2016. 
sujeitos. Seyferth (1999) define o termo como uma combinação entre a origem alemã e a cidadania brasileira, entre o pertencimento à nação alemã e ao mesmo tempo ao Estado brasileiro, enquanto visto como multirracial ou multiétnico. Assim, consideramos que o grupo não está diretamente ligado à nação alemã, mas ainda partilha traços ressignificados da cultura do país de origem dos imigrantes, principalmente através do uso da língua alemã.

2 Durante o governo Vargas, Nereu Ramos foi governador e interventor do estado de Santa Catarina, onde foi responsável pelo combate ao movimento nazista. Entendia-se, naquele período, que tal movimento estava vinculado a qualquer imigrante alemão, considerando-o uma ameaça à nação brasileira (Seyferth, 1997).

3 Esta investigação faz parte de uma pesquisa maior, de cunho qualitativo-interpretativista (Moita Lopes, 1994), financiada pelo Conselho Nacional de Desenvolvimento Científico e Tecnológico (CNPq), que teve como objetivo compreender como se deram os acessos ao(s) letramento(s) em língua alemã e em língua portuguesa por parte de indivíduos teuto-brasileiros que vivenciaram o período da segunda campanha de nacionalização do ensino (1937-1945) e o período pós-guerra. Parte dos dados discutidos neste artigo foram anteriormente socializados, com outro enfoque (Fritzen; Ewald, 2013).

4 Convenções de transcrição adaptadas de Marcuschi (1986): / - truncamentos bruscos, a fala é cortada; MAIÚSCULAS - o uso de maiúsculas indica ênfase ou acento forte; $(())$ - comentários do analista; [...] - o uso desse símbolo indica que parte da fala foi omitida, isto é, está transcrito apenas um trecho ou cortando parte do todo. Para preservar as identidades dos sujeitos e instituições, todos os nomes presentes nas transcrições das entrevistas são pseudônimos.

5 “[...] 'becoming literate' requires critical inter- and intra-personal identity work accomplished through engagement with cultural artifacts” (Bartlett, 2007, p. 52 , grifo no original).

\section{Referências}

BAKHTIN, Mikhail. Marxismo e Filosofia da Linguagem. Tradução: Michel Lahud e Yara Fratechi Vieira. 11. ed. São Paulo: Editora Hucitec, 2004.

BARTLETT, Lesley. To Seem and To Feel: Situated Identities and Literacy Practices. Teachers College Record, New York City, Columbia University, v. 109, n. 1, p. 51-69, 2007.

BAUER, Martin; GASKELL, George. Pesquisa Qualitativa com Texto, Imagem e Som. Petrópolis: Vozes, 2002.

BERENBLUM, Andrea. A Invenção Da Palavra Oficial: identidade, língua nacional e escola em tempos de globalização. Belo Horizonte: Autêntica, 2003.

BEZERRA, Maria Cristina dos Santos. Educação Étnica: a pluralidade das propostas educacionais de origem germânica no Estado de São Paulo. 2007. $232 \mathrm{f}$. Tese (Doutorado) - Programa de Pós-Graduação em Educação, Faculdade de Educação, Universidade Estadual de Campinas, Campinas, 2007.

BRASIL. Decreto-Lei no 406, de 04 de maio de 1938. Decreta questões relacionadas à entrada de estrangeiros no país. Coleção das Leis do Brasil, Rio de Janeiro, RJ. Disponível em: <http://www.planalto.gov.br/ccivil_03/Decreto-Lei/1937-1946/Del0406.htm>. Acesso em: 07 fev. 2016. 
$\underline{\text { Reflexões sobre Políticas de Educação Linguística em Contexto Plurilíngue }}$

CANDAU, Vera Maria Ferrão. Diferenças culturais, interculturalidade e educação em direitos humanos. Educação \& Sociedade, Campinas, v. 33, n. 118, p. 235-250, jan./mar. 2012.

CAVALCANTI, Marilda do Couto. Um olhar metateórico e metametodológico em pesquisa em linguística aplicada: implicações éticas e políticas. In: MOITA LOPES, Luiz Paulo (Org.). Por uma Linguística Aplicada Indisciplinar. São Paulo: Parábola Editorial, 2006. P. 233-252.

CAVALCANTI, Marilda do Couto. Bi/multilinguismo, escolarização e o (re)conhecimento de contextos minoritários, minoritarizados e invisibilizados. In: MAGALHÃES, Maria Cecília Camargo; FIDALGO, Sueli Salles; SHIMOURA, Alzira da Silva (Org.). A Formação no Contexto Escolar: uma perspectiva crítico-colaborativa. Campinas: Mercado de Letras, 2011. P. 171-185.

CAVALCANTI, Marilda do Couto. Educação linguística na formação de professores de línguas: intercompreensão e práticas translíngues. In: MOITA LOPES, Luiz Paulo (Org.). Linguística Aplicada na Modernidade Recente. São Paulo: Parábola, 2013. P. 211-226.

EWALD, Luana. "Essa mancha ficou!": memórias sobre práticas de letramento em cenário de imigração alemã. 2014. 110 f., il. Dissertação (Mestrado em Educação) - Programa de Pós-Graduação em Educação, Centro de Ciências da Educação, Universidade Regional de Blumenau, Blumenau, 2014. Disponível em: <http://www.bc.furb.br/docs/DS/2014/356452_1_1.pdf>. Acesso em: 07 fev. 2016.

FÁVERI, Marlene. Memórias de uma (outra) Guerra: cotidiano e medo durante a Segunda Guerra em Santa Catarina. Itajaí: Ed. Univali; Florianópolis: Ed. da UFSC, 2004

FRITZEN, Maristela Pereira. "Ich kann mein Name mit letra junta und letra solta schreiben": bilinguismo e letramento em uma escola rural localizada em zona de imigração alemã no Sul do Brasil. 2007. 305 f. Tese (Doutorado em Linguística Aplicada) - Instituto de Estudos da Linguagem, Universidade Estadual de Campinas, Campinas, 2007.

FRITZEN, Maristela Pereira; EWALD, Luana. "Aqui somos protegidos pelas nossas quatro paredes. Aqui nós falamos alemão": histórias de letramentos interculturais no Vale do Itajaí, SC. Trabalhos em Linguística Aplicada, Campinas, n. 52.2, p. 239-258, jul./dez. 2013.

FRITZEN, Maristela Pereira; EWALD, Luana. "Bilíngue? Só se eu tivesse um curso ou escrevesse diariamente": considerações sobre bilinguismo e educação em um contexto de línguas de imigração. Revista Atos de Pesquisa, Blumenau, v. 6, n. 1, p. 146-163, jan./abr. 2011.

HALL, Stuart. A Identidade Cultural na Pós-Modernidade. 10. ed. Rio de Janeiro: DP\&CA, 2005.

HALL, Stuart. A centralidade da cultura: notas sobre as revoluções culturais no nosso tempo. Educação \& Realidade, Porto Alegre, v. 22, n. 2, p. 17-46, jul./dez. 1997.

HOUAISS, Antonio; VILLAR, Mauro de Salles; FRANCO, Francisco Manoel de Mello. Dicionário Houaiss da Língua Portuguesa. Rio de Janeiro: Objetiva, 2001. P. 2925.

KREUTZ, Lúcio. Língua de referência na escola teuto-brasileira: as tensões entre o uso do alemão e do português. In: CUNHA, Jorge Luiz; GÄRTNER, Angelika (Org.). Imigração Alemã no Rio Grande do Sul: história, linguagem, educação. Santa Maria: EUFSM, 2003. P. 133-157.

510 Educação \& Realidade, Porto Alegre, v. 41, n. 2, p. 491-512, abr./jun. 2016. 
LORENZI, Estela Maris Bogo. Políticas linguísticas para o ensino de línguas em um cenário de imigração italiana no Vale do Itajaí, SC. 2014. 102 f. il. Dissertação (Mestrado em Educação) - Programa de Pós-Graduação em Educação, Centro de Ciências da Educação, Universidade Regional de Blumenau, Blumenau, 2014. Disponível em: <http://www.bc.furb.br/docs/DS/2014/357691_1_1.pdf>. Acesso em: 29 jan. 2016.

LUNA, José Marcelo Freitas. O Português na Escola Alemã de Blumenau: da formação à extinção de uma prática. Itajaí: Ed. da Univali; Ed. da Furb, 2000.

MAAS, Scheila. “Rais Aus, Die Polatzai Komm!”: os sentidos da língua alemã no ensino em Pomerode-SC. 95f. Dissertação (Mestrado em Educação) - Programa de Pós-Graduação em Educação, Universidade Regional de Blumenau, Blumenau, 2010.

MAHER, Terezinha Machado. Do casulo ao movimento: a suspensão das certezas na educação bilíngue e intercultural. In: CAVALCANTI, Marilda de Couto; BORTONI-RICARDO, Stella Maris (Org.). Transculturalidade, Linguagem e Educação. Campinas: Mercado de Letras, 2007a. P. 67-94.

MAHER, Terezinha Machado. A educação do entorno para a interculturalidade e o plurilinguismo. In: KLEIMAN, Angela Bustos; CAVALCANTI, Marilda do Couto (Org.). Linguística Aplicada: suas faces e interfaces. Campinas: Mercado de Letras, 2007b. P. 255-270.

MAILER, Valéria Contrucci de Oliveira. O Alemão em Blumenau: uma questão de identidade e cidadania. 2003. 95 f. Dissertação (Mestrado em Linguística) - Programa de Pós-Graduação em Linguística, Universidade Federal de Santa Catarina, Florianópolis, 2003.

MARCUSCHI, Luiz Antônio. Análise da Conversação. São Paulo: Ática, 1986.

MOITA LOPES, Luiz Paulo. Pesquisa interpretativista em Linguística Aplicada: a linguagem como condição e solução. DELTA - Revista de Documentação de Estudos em Linguística Teórica e Aplicada, São Paulo, v. 10, n. 2, p. 329-338, ago. 1994.

RAJAGOPALAN, Kanavillil. Por uma Linguística Crítica: linguagem, identidade e a questão ética. São Paulo: Parábola Editorial, 2003.

SEYFERTH, Giralda. A Estratégia do Branqueamento. Ciência Hoje, Rio de Janeiro, v. 5, n. 25, p. 54-56, 1986.

SEYFERTH, Giralda. A assimilação dos imigrantes como questão nacional. Mana - Estudos da Antropologia Social, Rio de Janeiro, v. 3, n. 1, p. 95-131, abril 1997.

SEYFERTH, Giralda. Etnicidade, Política e Ascensão Social: um exemplo teuto-brasileiro. Mana - Estudos de Antropologia Social, Rio de Janeiro, v. 5, n. 2, p. 61-88, 1999. Disponível em: <http://www.scielo.br/scielo.php?script=sci_ arttext\&pid=S0104-93131999000200003\&lng=pt\&nrm=iso $>$. Acesso em: 24 nov. 2014.

SEYFERTH, Giralda. A idéia de cultura teuto-brasileira: literatura, identidade e os significados da etnicidade. Horizontes Antropológicos, Porto Alegre, v. 10, n. 22, p. 149-197, jul./dez. 2004. Disponível em: <http://www.scielo.br/scielo.php?script=sci_arttext\&pid=S0104-71832004000200007>. Acesso em: 24 nov. 2014.

SILVA, Tomaz Tadeu. A produção social da identidade e da diferença. In: SILVA, Tomaz Tadeu (Org.). Identidade e Diferença: a perspectiva dos Estudos Culturais. 11. ed. Petrópolis: Vozes, 2012. P. 73-102. 
$\underline{\text { Reflexões sobre Políticas de Educação Linguística em Contexto Plurilíngue }}$

SILVA, José Ferreira. História de Blumenau. Florianópolis: Edeme, 1972.

SOUSA, Ivonete Mendes de. Práticas de Leitura na Escola Agrotécnica Federal de Codó-MA: Considerações sobre a Leitura Escolar. 71 f. Dissertação (Mestrado em Educação Agrícola) - Instituto de Agronomia, Universidade Federal Rural do Rio de Janeiro, Seropédica/RJ, 2010.

SPIESS, Viviane Beckert. Discursos sobre Ensino Bilíngue em Contexto Intercultural: as vozes das famílias. 2014. 139 f, il. Dissertação (Mestrado em Educação) - Programa de Pós-Graduação em Educação, Centro de Ciências da Educação, Universidade Regional de Blumenau, Blumenau, 2014. Disponível em: <http://www.bc.furb.br/docs/DS/2014/358742_1_1.pdf >. Acesso em: 29 jan. 2016.

YAGUELLO, Marina. Introdução. In: BAKHTIN, Mikhail. Marxismo e Filosofia da Linguagem. Tradução: Michel Lahud e Yara Fratechi Vieira. 11. ed. São Paulo: Editora Hucitec, 2004. P. 12-20.

Maristela Pereira Fritzen é professora do Programa de Mestrado em Educação e do Departamento de Letras da FURB (Universidade Regional de Blumenau). Doutora em Linguística Aplicada pela Unicamp (2007), com estágio de doutorado na Universidade de Freiburg (Alemanha), e Mestre em Educação pela FURB (1999).

E-mail:mpfritzen@gmail.com

Luana Ewald é mestre em Educação pela FURB. Professora do Departamento de Letras da mesma instituição.

E-mail: luanaewald@gmail.com 